\title{
More than skin deep: Paget's disease of the perineum
}

Hong Kong Med J 2014;20:264.e1-2

DOI: 10.12809/hkmj133983

In July 2012, an extensive eczematous lesion was found incidentally over the external genitalia in a 77-year-old man who was being evaluated for lower limb cellulitis. The affected area had been present for 10 years; it was erythematous, macerated, and itchy. He had consulted countless doctors, but the itchiness was intense and the area of involvement was enlarging despite application of topical creams. On physical examination, the perineum was weepy with excoriation, crusts, and a serous discharge. The erythematous skin was indurated and had a well-defined margin. The penis shaft was swollen with palpable groin lymph nodes (Fig 1). Blood tests showed eosinophilia $\left(1.1 \times 10^{9} / \mathrm{L}\right)$ and an elevated erythrocyte sedimentation rate $(58 \mathrm{~mm} / \mathrm{h})$.

A clinical suspicion of extramammary Paget's disease (EMPD) was suggested by the dermatologist. Skin biopsy of the right suprapubic region confirmed the diagnosis (Fig 2), while another biopsy of the left groin showed poorly differentiated invasive carcinoma, consistent with invasive EMPD. Urine for cytology, as part of the malignancy screening, showed atypical cells. Computed tomography of

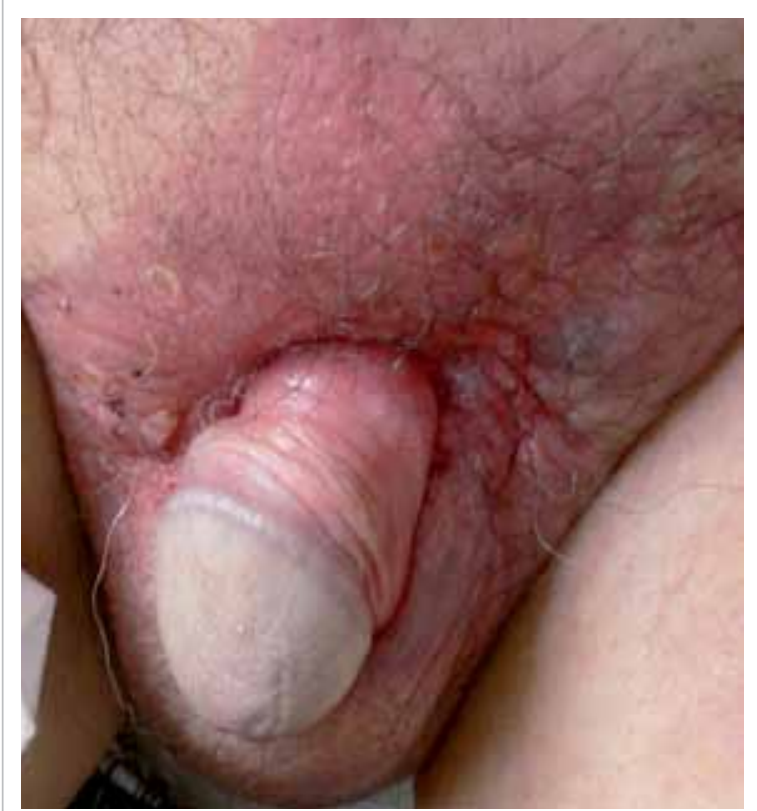

FIG I. Clinical picture of extramammary Paget's disease of the perineum, showing its weepy nature and the sharp margin around the affected area the abdomen revealed left ureteric obstruction with enhanced mural thickening of left ureter, of which transitional cell carcinoma could not be excluded. He was referred to a urologist for further assessment. Radiotherapy to the affected skin lesions was given in view of the extensive involvement.

Extramammary Paget's disease is a rare intraepithelial adenocarcinoma of the skin rich in apocrine glands, first described by Crocker in 1888. ${ }^{1}$ The disease involves the epidermis, but can potentially metastasise via the lymphatic system. ${ }^{2}$ Its clinical and histological features are similar to Paget's disease of the nipple. The penis, scrotum, and vulva are frequently involved in sites. The erythematous area has a sharp margin and scaly surface. Intense itchiness is common and may result in erosion, excoriation, and lichenification. ${ }^{2}$

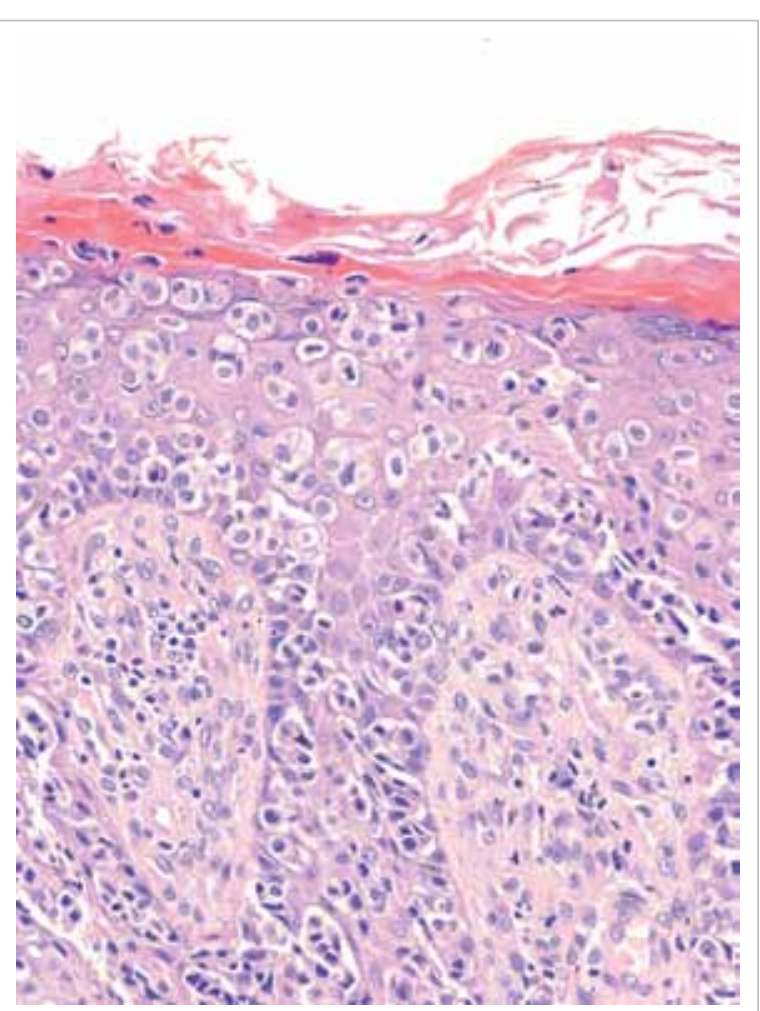

FIG 2. The skin biopsy taken from the right suprapubic area shows many nests of cohesive pleomorphic malignant cells invading the epidermis. Immunohistochemical study demonstrates that the tumour cells are cytokeratin (CAM5.2) positive (not shown), confirming their epithelial nature (H\&E; original magnification, $\times$ 200) 
Our patient had a typical presentation with longstanding, distressing, and difficult-to-treat, eczema-like perineal lesion with a well-defined border. Delay in diagnosis, up to a decade, ${ }^{3}$ is notoriously common, because EMPD often mimics benign dermatological diseases such as eczema, contact dermatitis and fungal infection, and even malignant skin conditions like superficial melanoma, basal cell carcinoma, and Bowen's disease.

A clinical diagnosis should be confirmed by skin biopsy. Immunohistochemistry shows the cells are positive for CEA, CAM 5.2, as well as keratins CK7 and 8. Once EMPD is diagnosed, thorough search for malignancy is mandatory, since up to $37 \%$ of patients have associated malignancies, in which case the condition is referred to as secondary EMPD. ${ }^{4} \mathrm{~A}$ recent study among Chinese patients showed that $8.3 \%$ out of 48 patients with EMPD developed malignancy. ${ }^{3}$ Location of skin involvement in EMPD predicts the type of cancer; perianal lesions are associated with anal and colorectal cancer, whereas penoscrotal lesions tend to be associated with urogenital malignancies. ${ }^{4}$ The positivity of Cytokeratin 20 in immunostaining is also highly associated with internal malignancies. ${ }^{5}$

Treatment is mainly surgical resection with reconstruction. Radiotherapy is an adjunctive therapy or reserved for frail elderly patients. ${ }^{2}$ Photodynamic therapy and topical imiquimod have been used. Despite these treatments, the local recurrence rate still ranges from $21 \%$ to $61 \%,{ }^{3}$ with a median time to recurrence of 2 years.

\section{Acknowledgement}

We would like to thank Dr Shun-chin $\mathrm{Ng}$, Dermatologist, Department of Health, Hong Kong, for his clinical care and manuscript advice. We thank Dr Wing-hung Lau, Department of Pathology, Queen Elizabeth Hospital, for provision of histological diagnosis and picture.

JW Li *, MB, BS, MRCP

$\mathrm{CM} \mathrm{Ng}$, MRCP, FHKAM

Department of Medicine, Queen Elizabeth Hospital, 30 Gascoigne Road, Kowloon, Hong Kong

* Corresponding author: lijohnwing@gmail.com

\section{References}

1. Crocker HR. Paget's disease affecting the scrotum and penis. Trans Pathol Soc Lond 1888;40:187-91.

2. Burns T, Breathnach S, Cox N, Griffiths C, editors. Rook's textbook of dermatology. 8th ed. Oxford, UK: WileyBlackwell; 2010.

3. Chan JY, Li GK, Chung JH, Chow VL. Extramammary Paget's disease: 20 years of experience in Chinese population. Int J Surg Oncol 2012;2012:416418.

4. Sarmiento JM, Wolff BG, Burgart LJ, Frizelle FA, Ilstrup DM. Paget's disease of the perianal region-an aggressive disease? Dis Colon Rectum 1997;40:1187-94.

5. Liegl B, Liegl S, Gogg-Kamerer M, Tessaro B, Horn LC, Moinfar F. Mammary and extramammary Paget's disease: an immunohistochemical study of 83 cases. Histopathology 2007;50:439-47. 